\title{
Elemental Composition and Water Content of Rat Optic Nerve Myelinated Axons and Glial Cells: Effects of in vitro Anoxia and Reoxygenation
}

\author{
Richard M. LoPachin, Jr.,' and Peter K. Stys ${ }^{2}$ \\ 'Department of Anesthesiology, Albert Einstein College of Medicine, Montefiore Medical Center, Bronx, New York \\ 10467-2490 and 'Loeb Research Institute, Ottawa Civic Hospital, University of Ottawa, Ottawa, Ontario, Canada \\ K1Y 4E9
}

\begin{abstract}
Electron probe $\mathrm{x}$-ray microanalysis was used to measure water content and concentrations ( $\mathrm{mmol} / \mathrm{kg}$ dry weight) of elements ( $\mathrm{Na}, \mathrm{P}, \mathrm{S}, \mathrm{Cl}, \mathrm{K}, \mathrm{Ca}$, and $\mathrm{Mg}$ ) in myelinated axons and glial cells of rat optic nerve exposed to in vitro anoxia and reoxygenation. In response to anoxia, large, medium, and small diameter fibers exhlbited an early $(5 \mathrm{~min})$ and progressive loss of $\mathrm{Na}$ and $\mathrm{K}$ regulation which culminated $(60 \mathrm{~min})$ in severe depletion of respectlve transmembrane gradients. As axoplasmic $\mathrm{Na}$ levels increased during anoxic exposure, a parallel rise in $\mathrm{Ca}$ content was noted. For all axons, mean water content decreased progressively during the initial $\mathbf{1 0}$ min of anoxia and then returned toward normal values as anoxia continued. Analyses of mitochondrial areas revealed a similar pattern of elemental disruption except that $\mathrm{Ca}$ concentrations rose more rapidly during anoxia. Following $60 \mathrm{~min}$ of postanoxia reoxygenation, the majority of larger fibers displayed little evidence of recovery, whereas a subpopulation of small axons exhibited a trend toward restoration of normal elemental composition. Glial cells and myelin were only modestly affected by anoxia and subsequent reoxygenation. Thus, anoxic injury of CNS axons is associated with characteristic changes in axoplasmic distributions of $\mathrm{Na}, \mathrm{K}$, and $\mathrm{Ca}$. The magnitude and temporal patterns of elemental $\mathrm{Na}$ and $\mathrm{Ca}$ disruption are consistent with reversal of $\mathrm{Na}^{+}-\mathrm{Ca}^{2+}$ exchange and subsequent $\mathrm{Ca}$ entry (Stys et al., 1992). During reoxygenation, elemental deregulation continues for most CNS fibers, although a subpopulation of small axons appears to be capable of recovery.
\end{abstract}

[Key words: anoxia, reperfusion, axon injury, myelinated axons, glial cells, optic nerve, elements, electron probe $x$-ray microanalysis, $\mathrm{Na}^{+}-\mathrm{Ca}^{2+}$ exchanger]

It has been hypothesized that the injury to myelinated axons caused by CNS white matter anoxia or hypoxia is mediated by a cascade of events initiated by ATP depletion and resulting

Received Nov. 7, 1994; revised May 31, 1995; accepted June 9, 1995.

We thank Renu Doshi, Edward Stack, and James Surowiak for their excellent technical help. We are indebted to Dr. Ellen Lehning for her helpful and critical comments. This publication was made possible by Grant RO1 ES03830 from NIEHS (R.M.L.) and by Medical Research Council of Canada Grant MT11595 M (P.K.S.).

Correspondence should be addressed to Richard M. LoPachin, Ph.D., Montefiore Medical Center, Anesthesia Research-Moses 7, 111 East 210th Street, Bronx, NY 10467.

Copyright (C) 1995 Society for Neuroscience 0270-6474/95/156735-12\$05.00/0 inhibition of axolemmal $\mathrm{Na}^{+} / \mathrm{K}^{+}$-ATPase activity. The subsequent rise in axonal $\mathrm{Na}^{+}$, in conjunction with membrane depolarization, promotes reverse operation of the $\mathrm{Na}^{+}-\mathrm{Ca}^{2+}$ exchanger and damaging influx of $\mathrm{Ca}^{2+}$ (Ransom et al., 1992; Stys et al., $1990,1991,1992)$. Although this initial ionic disruption is likely to be of primary pathophysiological significance, CNS oxygen deprivation in vivo is often transient and is followed by reoxygenation. Evidence suggests that, despite restoration of normal regional CNS oxygen content, the reoxygenation (reperfusion) period is associated with further axonal injury. This secondary injury is presumably a consequence of free radical generation and additional $\mathrm{Na}^{+}$and $\mathrm{Ca}^{2+}$ entry in axons (Young, 1986; Siesjo, 1988). Since excess $\mathrm{Ca}^{2+}$ can mediate irreversible injury, axonal accumulation of this ion might underlie the paradoxical "maturation" of anoxic damage that presumably occurs during reoxygenation (Farber et al., 1981; Young, 1986; Siesjo, 1988). The mechanism of $\mathrm{Ca}^{2+}$ influx during reoxygenation injury is unknown but, like anoxia, might involve the $\mathrm{Na}^{+}-\mathrm{Ca}^{2+}$ exchanger. Regardless, these findings suggest that loss of $\mathrm{Na}^{+}, \mathrm{K}^{+}$and $\mathrm{Ca}^{2+}$ regulation during anoxia and subsequent reoxygenation is responsible for changes in the structure and function of myelinated axons. To investigate this possibility, we have used electron probe $\mathrm{x}$-ray microanalysis to determine the distribution of $\mathrm{Na}$, $\mathrm{K}, \mathrm{Ca}$, and other elements in myelinated axons of rat optic nerve. The elemental composition of resident glial cells was also assessed based on the potential involvement of these cells in anoxic and reperfusion injury (Kimelberg and Ransom, 1986; Kim-Lee et al., 1992; Ransom and Philbin, 1992).

Due to the small dimensions of myelinated axons and glial processes in mammalian CNS, it is technically difficult to measure ionic concentrations using conventional methods such as fluorescent dyes or ion-selective microelectrodes. Similarly, tissue-level measurements using atomic absorption spectrophotometry or radioisotope fluxes cannot distinguish glial- versus axonspecific changes in clemental composition that evolve during anoxia or reoxygenation. Electron probe $\mathrm{x}$-ray microanalysis (EPMA) is a quantitative electron microscopy technique that measures both water content and total (free plus bound) concentrations of elements (e.g., $\mathrm{Na}, \mathrm{K}, \mathrm{Ca}$ ) in cellular morphological compartments (for detailed methodological and theoretical considerations see review by LoPachin and Saubermann, 1990). Thus, unlike other methods of ion/element measurement, EPMA permits differentiation of nervous tissue cell types (i.e., glia vs axon) and subsequent analyses of intracellular morphological compartments (e.g., mitochondria). Since compensatory changes 
in cell water accompany injury-induced ion shifts (Macknight, 1988), EPMA measurements of compartmental water content allow calculation of molar concentrations and, consequently, estimation of the pathophysiological relevance of anoxia-induced elemental alterations.

Previous EPMA studies have demonstrated that CNS and PNS myelinated axons and glial cells exhibit characteristic subcellular distributions of elements and water (LoPachin et al., 1988, 1991) and that experimental peripheral myelinated axon injury (e.g., axotomy, diabetes, chemical intoxication) produces specific, temporally dependent alterations in these distributions (LoPachin et al., 1990, 1992, 1993). Results of the present study indicate that in vitro optic nerve anoxia produces alterations in axonal $\mathrm{Na}, \mathrm{K}$, and $\mathrm{Ca}$ distributions that are consistent with the $\mathrm{Na}^{+}$$\mathrm{Ca}^{2+}$ exchanger hypothesis of Stys and colleagues (1992). Following $60 \mathrm{~min}$ of postanoxia reoxygenation, the majority of larger fibers displayed little evidence of recovery, although a subpopulation of small axons exhibited a trend toward restoration of normal elemental composition. We also report that the elemental composition of glial cells and myelin was only modestly affected during both anoxia and the reoxygenation period.

\section{Materials and Methods}

In vitro anoxia and reoxygenation of rat optic nerve. Adult Long Evans rats aged 50-70 d were anesthetized with $80 \% \mathrm{CO}_{2} / 20 \% \mathrm{O}_{2}$ and decapitated. Rat optic nerves (RONs, approximately $8 \mathrm{~mm}$ in length) were dissected free and were placed in an interface brain slice chamber (Medical Systems Corp., Greenvale, NY) and perfused at $3 \mathrm{ml} / \mathrm{min}$ with artificial cerebrospinal fluid (aCSF) containing (in mM): $\mathrm{NaCl} 126, \mathrm{KCl}$ 3.0, $\mathrm{MgSO}_{4}$ 2.0, $\mathrm{NaHCO}_{3} 26, \mathrm{NaH}_{2} \mathrm{PO}_{4} 1.25, \mathrm{CaCl}_{2} 2.0$, dextrose 10, $\mathrm{pH} 7.45$, maintained at $37^{\circ} \mathrm{C}$ (Stys et al., 1992). Isolated RONs were incubated for at least $60 \mathrm{~min}$ in aCSF aerated with a $95 \% \mathrm{O}_{2}, 5 \% \mathrm{CO}_{2}$ gas mixture. At the completion of this initial normoxic control period, RONs were either removed from the chamber $(t=0 \mathrm{~min}, n=3)$ or were subjected to anoxia for varying periods by switching to a $95 \%$ $\mathrm{N}_{2}, 5 \% \mathrm{CO}_{2}$ gas mixture ( $t=2.5-60 \mathrm{~min} ; n=3-4$ per time point). Once removed from the chamber, normoxic control $(t=0)$ and anoxic nerves were immediately quench frozen by immersion in melting Freon 22 (Chlorodifluoromethane, Aldrich) and then stored in liquid nitrogen until analysis. As a control for the in vitro anoxic period, RONs $(n=$ 2) were maintained in normoxic conditions for 60 min beyond the initial equilibrium period $(t=60)$. To investigate reoxygenation, RONs $(n=$ 3) were subjected to $60 \mathrm{~min}$ of anoxia as described above and then returned to normoxic conditions for $60 \mathrm{~min}$. At the completion of this postanoxic reoxygenation period, RONs were removed from the chamber and cryopreserved (see above). As a control for the reoxygenation study, nerves $(n=2)$ were incubated in normoxic aCSF for $120 \mathrm{~min}$ beyond the initial equilibrium period $(t=120)$.

Cryoultramicrotamy and electron probe $x$-ray microanalysis (EPMA). The methodologies for cryoultramicrotomy and EPMA have been published extensively (Saubermann et al., 1981a,b; Saubermann and Heyman, 1987; Foster and Saubermann, 1991; LoPachin et al., 1991). Briefly, frozen RONs were sectioned (500 nm nominal thickness) on a cryomicrotome at an ambient cryochamber temperature of $-55^{\circ} \mathrm{C}$. Unstained, unfixed, hydrated cryosections were then transferred under vacuum to the cold stage $\left(-185^{\circ} \mathrm{C}\right)$ of an AMRay 1400 scanning electron microscope. The electron microscope was equipped with a Tracor Northern energy dispersive detector and pulse processor which was connected to a PC based multichannel analyzer for collection and processing of $x$-rays.

For quantitative analyses of elements in optic nerve cryosections, wet weight specimen mass was measured in frozen hydrated sections by determining continuum generation rates (Saubermann et al., 1981a,b; Saubermann and Heyman, 1987). Cryosections were then dehydrated in the electron microscope column vacuum by raising the temperature of the cold stage from $-185^{\circ} \mathrm{C}$ to $-60^{\circ} \mathrm{C}$ for $30 \mathrm{~min}$. Stage temperature was returned to $-185^{\circ} \mathrm{C}$ for microanalysis. Morphological compartments were visualized in dehydrated cryosections using scanning transmission electron microscopy (STEM). The electron beam ( $20 \mathrm{keV}, 0.4$ $\mathrm{nA}$ current) was rastered within anatomical boundaries of the chosen structures. X-Ray spectra were collected over $100 \mathrm{sec}$ of live counting time. Dry weight elemental mass fractions (mmol/kg dry weight) for $\mathrm{Na}, \mathrm{K}, \mathrm{Cl}, \mathrm{S}, \mathrm{Mg}, \mathrm{P}$, and $\mathrm{Ca}$ were determined using software applying the Hall et al. (1973) method of continuum normalization (Foster and Saubermann, 1991). Water content (\% water) of morphological compartments was determined by the ratio of continuum counts in the hydrated and dried states (Bulger et al., 1981; Saubermann et al., 1981b). As indicated above, EPMA does not distinguish ionic versus bound element. Therefore, symbols for each element are expressed without valences (e.g., $\mathrm{Na}$ ) when corresponding concentrations have been derived by EPMA. Valences are indicated (e.g., $\mathrm{Na}^{+}$) for discussions of previous research involving ion-sensitive measurements or for physiological processes (e.g., membrane transport) where involvement of the ionized species is implicit (see Discussion).

In cryosections of optic nerve, myelinated axons were classified as either small $(<1 \mu \mathrm{m})$, medium $(1-2 \mu \mathrm{m})$ or large $(>2 \mu \mathrm{m})$ diameter fibers (Fig. 1). For each class of nerve fiber, elemental composition and water content was determined in axoplasm, mitochondria, and myelin. The majority of axoplasm analyzed in transverse cryosections was of internodal origin. Paranodal and nodal regions were also identified and analyzed, although the small number of respective analyses precluded statistical evaluation. For each axon size group of the reoxygenation study, the frequency data for dry weight axoplasmic $\mathrm{K}$ and Na concentrations are expressed as percentiles (see Figs. 5 and 6, respectively). Presentation of percentile graphs permits easy identification of axon subpopulations and the expression of individual fiber data, that is, for each axon analyzed the concentration of element is indicated. Moreover, the dispersion or heterogeneity of the data can be discerned by visual inspection and, since all groups of data (Normoxia, Anoxia and Reoxygenation) can be displayed on a single graph, comparisons among experimental groups can be readily made.

The mitochondrial compartment (Fig. 1) has been identified according to both functional (e.g., differential response to injury, Ca sequestration) and gross structural (e.g., size, shape, and orientation) criteria and is designated as "mitochondrial area" (LoPachin et al., 1991, 1992, 1993). Mitochondrial data represent analyses pooled primarily from organelles in large and medium fibers since mitochondria from small fibers were difficult to identify conclusively. Glial cell cytoplasm and myelin (Fig. 1) were also analyzed. The former compartment was represented primarily by glial processes (LoPachin et al., 1991). The respective elemental compositions of myelin from large, medium, and small diameter axons did not differ statistically and the data were therefore pooled.

Statistics. One-way analysis of variance (ANOVA) was used to determine whether analyses from individual animals of an experimental group could be pooled as independent data to derive a group mean. Therefore, descriptive parameters such as group means and variances are not based on the number of RONs (i.e., 3-4/time point), but rather are derived from pooled axon data. As in previous studies of myelinated axon injury (LoPachin et al., 1992, 1993), two types of statistically significant changes were determined in the present investigation: nonparametric increases in variance (i.e., heterogeneity or increased dispersion) and parametric shifts in group mean data. For nonparametric analyses, squared deviates from within groups were calculated and a Kruskal-Wallis test was applied among groups. A Mann-Whitney $U$ test with Bonferroni correction was used to determine differences $(p<0.05)$ between control and anoxia group data (variance). For parametric analyses, statistical differences $(p<0.05)$ among group means were determined using one-way ANOVA. Treatment versus control mean differences $(p<0.05)$ were assessed using Dunnett's $t$ test.

\section{Results}

\section{Morphological observations}

Myelinated axons and glial cells in cryosections from preanoxic $(t=0)$ and normoxic control $(t=60,120 \mathrm{~min})$ nerves exhibited morphology that was similar to that described in a previous EPMA study of in situ rat optic nerve (LoPachin et al., 1991). Moreover, morphological features in frozen section were comparable to those observed in conventionally fixed thin sections of rat optic nerve exposed to equivalent in vitro control incubation conditions (Waxman et al., 1992). Figure $1 A$ is a low-magnification scanning-transmission electron micrograph (STEM) image of normoxic ( $t=60^{\prime}$ control) optic nerve in transverse cryosection. 

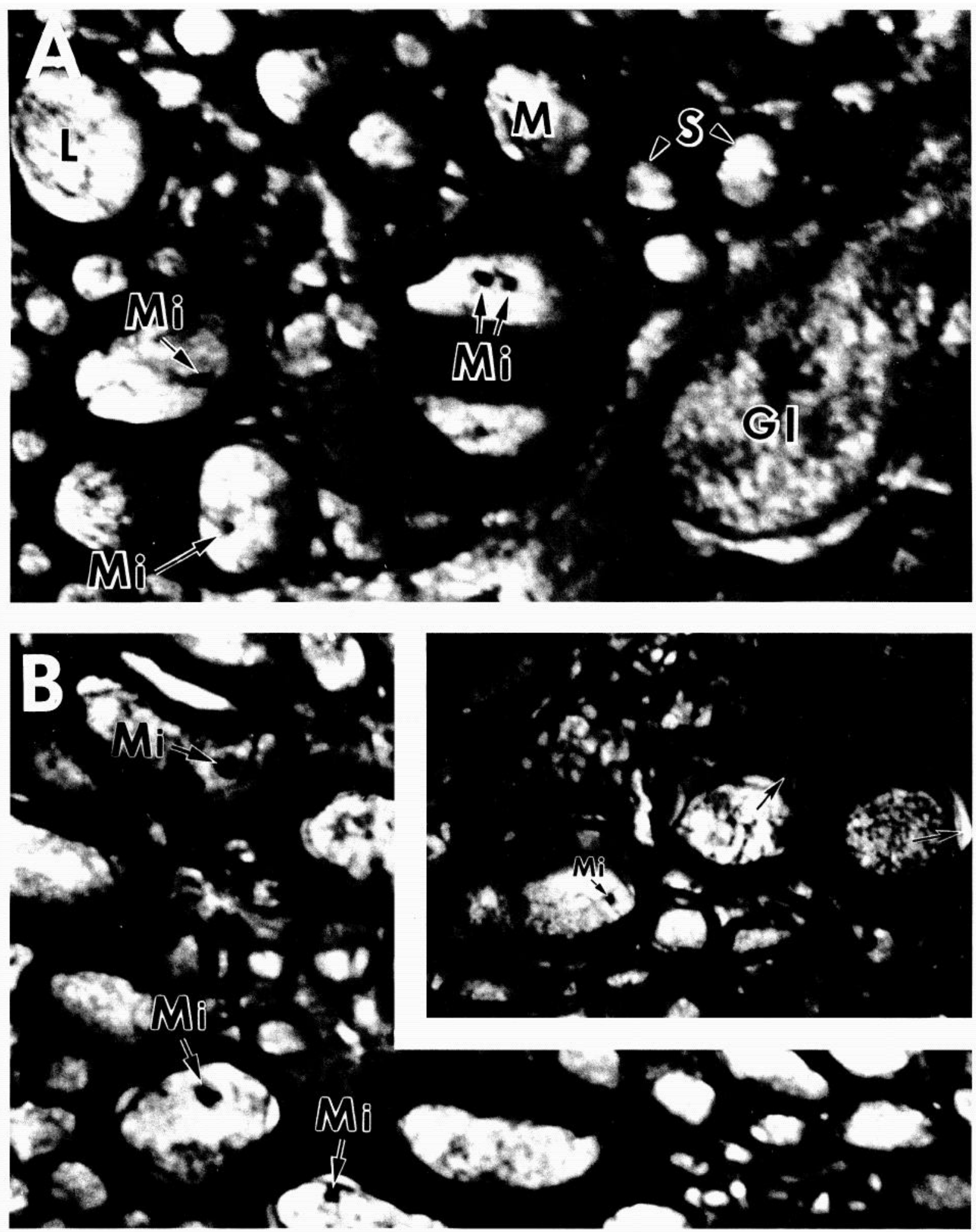

Figure 1. A, Scanning-transmission electron micrograph (STEM) of a frozen, unstained dehydrated transverse cryosection from normoxic control $\left(t=60^{\prime}\right)$ rat optic nerve. Small ( $S$ arrow), medium $(M)$, and large $(L)$ diameter myelinated axons are indicated. Also identified are mitochondria (Mi arrows) and a glial cell area $\left(\mathrm{Gl}\right.$ ). Despite in vitro incubation for a total of $120^{\prime}$, axonal and glial morphological characteristics are comparable to those of cryosections from optic nerve prepared in situ (see LoPachin et al., 1991). A, 13,500×; $B$, STEM image showing optic nerve morphology following 60' of in vitro anoxia. Numerous intramyelinic vacuoles are evident primarily associated with larger diameter fibers (arrows, inset). Many respective mitochondria (Mi arrows) are enlarged. B, 15,000×; inset, 12,000×. 
Table 1. Elemental composition and water content of control rat optic nerve compartments

\begin{tabular}{|c|c|c|c|c|}
\hline & In situ (4) & $\begin{array}{l}\text { Dissection } \\
\text { (2) }\end{array}$ & $\begin{array}{l}\text { Preanoxia } \\
(3) \\
" t=0 "\end{array}$ & $\begin{array}{l}\text { Normoxia } \\
(2) \\
" t=60 "\end{array}$ \\
\hline \multicolumn{5}{|c|}{ Medium axons } \\
\hline $\mathrm{Na}$ & $194 \pm 13$ & $308 \pm 19 *$ & $202 \pm 17$ & $202 \pm 18$ \\
\hline $\mathbf{P}$ & $461 \pm 23$ & $538 \pm 19$ & $617 \pm 22$ & $702 \pm 57$ \\
\hline $\mathrm{Cl}$ & $335 \pm 14$ & $197 \pm 22$ & $405 \pm 27$ & $441 \pm 45$ \\
\hline $\mathrm{K}$ & $1465 \pm 56$ & $1008 \pm 122^{*}$ & $1580 \pm 105$ & $1596 \pm 167$ \\
\hline $\mathrm{Ca}$ & $3 \pm 2$ & $7 \pm 3$ & $6 \pm 1$ & $4 \pm 3$ \\
\hline $\mathrm{Mg}$ & $27 \pm 3$ & $35 \pm 8$ & $39+6$ & $33 \pm 7$ \\
\hline $\mathrm{H}_{2} \mathrm{O}$ & $91 \pm 0$ & $91 \pm 0$ & $90 \pm 1$ & $89 \pm 1$ \\
\hline$n_{\mathrm{ax}}$ & 56 & 25 & 43 & 26 \\
\hline \multicolumn{5}{|c|}{ Glial areas } \\
\hline $\mathrm{Na}$ & $147 \pm 12$ & $345 \pm 31^{*}$ & $189 \pm 15$ & $218 \pm 21$ \\
\hline $\mathbf{P}$ & $636 \pm 38$ & $712 \pm 40$ & $795 \pm 25$ & $825 \pm 43$ \\
\hline $\mathrm{Cl}$ & $151 \pm 18$ & $211 \pm 19$ & $91 \pm 10$ & $105 \pm 15$ \\
\hline $\mathbf{K}$ & $458 \pm 27$ & $536 \pm 36$ & $541 \pm 26$ & $487 \pm 52$ \\
\hline $\mathrm{Ca}$ & $0 \pm 1$ & $2 \pm 1$ & $6 \pm 1$ & $0 \pm 2$ \\
\hline $\mathrm{Mg}$ & $38 \pm 5$ & $40 \pm 7$ & $52 \pm 4$ & $42 \pm 8$ \\
\hline $\mathrm{H}_{2} \mathrm{O}$ & $80 \pm 1$ & $78 \pm 1$ & $80 \pm 1$ & $78 \pm 2$ \\
\hline$n_{\mathrm{gl}}$ & 24 & 18 & 24 & 27 \\
\hline
\end{tabular}

Elemental data are expressed as mean mmol/kg dry wt \pm SEM; $\mathrm{H}_{2} \mathrm{O}$ data are expressed as mean \% water \pm SEM. "In situ" data are from LoPachin et al. (1991). Disscction, preanoxia $(t-0)$, and normoxia $(t=60)$ controls are as described in Methods and Materials. Numbers in parentheses represent number of rats per experimental group. $n_{\mathrm{ax}}$, total number of axons analyzed per group; $n_{\mathrm{g}}$, total number of glial areas analyzed per group.

* Significantly $(p<0.05)$ different form preanoxia control as determined by ANOVA with Dunnett's $t$ test.

Small, medium and large diameter axons are evident as well as glial cell areas. Mitochondrial areas in STEM images appear as electron-opaque, ovoid, or elongated structures, depending upon the plane of section (Fig. $1 A$ ). In cryosections of anoxic optic nerve, morphological alterations followed a pattern of development and expression similar to that reported by Waxman et al., (1992, 1993). Thus, Figure $1 B$ is a low-magnification STEM image showing a transverse cryosection of optic nerve exposed to anoxic conditions for $60^{\prime}$. Large, intramyelinic spaces adjacent to irregular axonal profiles were the most prominent morphological feature of these cryosections (Fig. 1, inset). In addition, many of the respective mitochondria were enlarged (Fig. 1). These structural changes were primarily associated with large-diameter fibers.

\section{Electron probe x-ray microanalysis (EPMA) of anoxic and reoxygenated optic nerves}

Elemental composition of axons and glia from in vitro normoxic control optic nerves. Table 1 presents EPMA data from medium diameter axons and glial areas under in situ (LoPachin et al., 1991) and control in vitro incubation conditions. Following dissection, myelinated axons (e.g., medium axons, Table 1) and corresponding mitochondrial areas (data not shown) exhibit significant decreases in axoplasmic $\mathrm{K}$ and slight increases in $\mathrm{Na}$ relative to the preanoxic control $(t=0)$. Similar changes were observed in large and small diameter fibers (data not shown). We also found that the elemental composition of axons incubated for 120 min under normoxic conditions were comparable to respective compartments from in situ optic nerves $(t=60$, Table 1). Together, these findings suggest that nerve dissection was associated with axon injury as indicated by modest elemen-

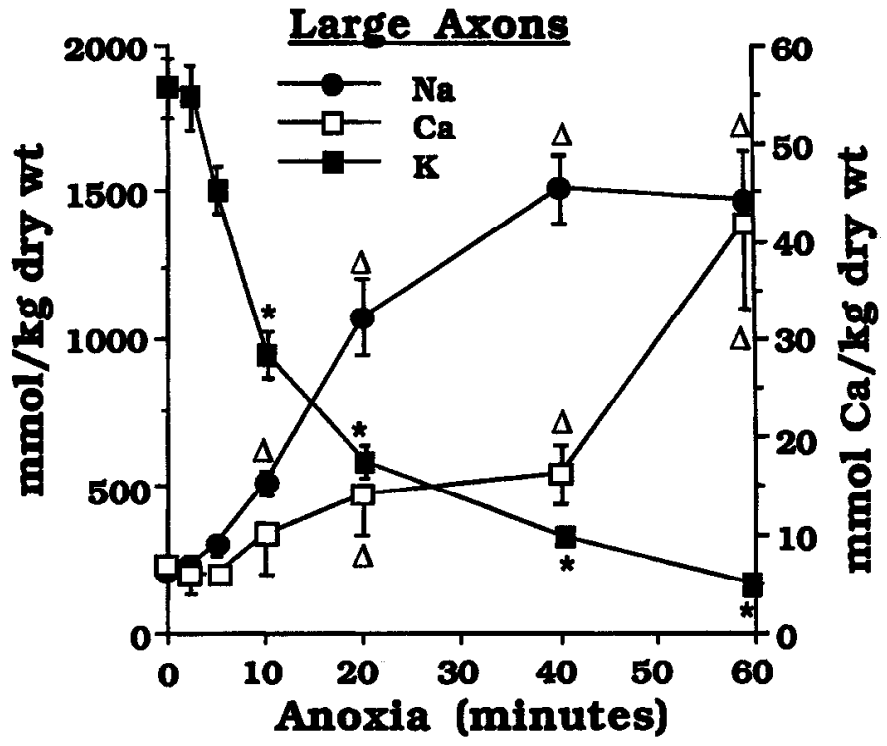

Figure 2. Effects of anoxia on mean ( \pm SEM) axoplasmic dry weight $\mathrm{Na}, \mathrm{Ca}$, and $\mathrm{K}$ concentrations of large diameter optic nerve fibers. Left ordinate is concentration scale for $\mathrm{Na}$ and $\mathrm{K}$; right ordinate is the scale for $\mathrm{Ca}$. *, Mean data are significantly different $(p<0.05)$ from normoxic control as determined by ANOVA with Dunnett's $t$ test; $\Delta$, data variance is significantly different $(p<0.05)$ from that of normoxic control as determined by Kruskal-Wallis test with Mann-Whitney $U$ test. Number of fibers analyzed per experimental time point is provided in Table 2.

tal derangement (see review by LoPachin and Saubermann, 1990). However, this injury was reversible since during normoxic control incubations (Table 1), elemental composition recovered to in situ levels. Results also indicated that the elemental composition and water content of glial cells (Table 1) and myelin (data not shown) remained relatively unaffected following dissection or normoxic incubation. Finally, statistical comparisons of respective elemental data among controls $(t=0,60,120)$ revealed no differences and, therefore, the data were pooled as a common normoxic control for the anoxia and reoxygenation data (normoxia; see Tables 2-5 and Figs. 2-7).

Effects of anoxia and reoxygenation on elemental composition and water content of rat optic nerve myelinated axons. In vitro rat optic nerve anoxia produced progressive changes in myelinated axon elemental composition and water content. For example, in axoplasm of large fibers, statistically significant and progressive decreases in mean dry weight $\mathrm{K}$ concentrations were observed (Fig. 2). In contrast, large axon $\mathrm{Na}$ levels increased steadily during the initial $40 \mathrm{~min}$ of anoxia and then remained constant (Fig. 2). For each anoxia time point, both the minimum and maximum $\mathrm{Na}$ concentrations (mmol/kg dry $\mathrm{wt}$ ) increased progressively with concomitant widening of the data range, for example, normoxic control (minimum-maximum) $=60-485$, $10^{\prime}$ anoxia $=195-1011,60^{\prime}$ anoxia $=338-4335$. In addition, the corresponding dispersion of each data set was skewed toward higher $\mathrm{Na}$ concentrations resulting in a non-normal distribution. Accordingly, nonparametric statistics (see Materials and Methods) revealed significant increases in respective variance. Overall, the extent of anoxia-induced $\mathrm{K}$ loss in large axons was greater than the gain in $\mathrm{Na}$ (Fig. 2). Consequently, after $60 \mathrm{~min}$ of anoxia there was a $17 \%$ net deficit in total mean cationic elemental composition of large axons relative to that of normoxic control (see $\mathrm{Mg}$ and $\mathrm{Ca}$ changes below). Mean axoplasmic $\mathrm{Ca}$ 
Table 2. Elemental composition and water contents of myelinated axons and mitochondrial areas

\begin{tabular}{|c|c|c|c|c|c|c|c|}
\hline & \multirow[b]{2}{*}{ Normoxia } & \multicolumn{6}{|c|}{ Anoxia (min) } \\
\hline & & 2.5 & 5 & 10 & 20 & 40 & 60 \\
\hline \multicolumn{8}{|c|}{ Large axons } \\
\hline $\mathrm{P}$ & $629 \pm 24$ & $675 \pm 32$ & $575 \pm 23$ & $553 \pm 35$ & $560 \pm 48$ & $581 \pm 33$ & $592 \pm 25$ \\
\hline $\mathrm{Cl}$ & $492 \pm 23$ & $482 \pm 27$ & $478 \pm 32$ & $355 \pm 30^{*}$ & $446 \pm 53 \dagger$ & $441 \pm 30$ & $542 \pm 69 \dagger$ \\
\hline $\mathrm{Mg}$ & $36 \pm 4$ & $42 \pm 6$ & $28 \pm 5$ & $26 \pm 5$ & $27 \pm 7$ & $15 \pm 4^{*}$ & $6 \pm 2^{*}$ \\
\hline $\mathrm{H}_{2} \mathrm{O}$ & $91 \pm 0$ & $91 \pm 0$ & $89 \pm 1$ & $87 \pm 1^{*}$ & $89 \pm 1$ & $93 \pm 1$ & $91 \pm 1$ \\
\hline$n$ & 69 & 37 & 40 & 32 & 30 & 50 & 34 \\
\hline \multicolumn{8}{|c|}{ Medium axons } \\
\hline $\mathrm{P}$ & $663 \pm 23$ & $780 \pm 43^{*}$ & $606 \pm 29$ & $548 \pm 33$ & $669 \pm 39$ & $635 \pm 25$ & $526 \pm 30^{*}$ \\
\hline $\mathrm{Cl}$ & $426 \pm 22$ & $378 \pm 20$ & $389 \pm 21$ & $268 \pm 20^{*}$ & $359 \pm 31$ & $357 \pm 29$ & $457 \pm 46 \dagger$ \\
\hline $\mathrm{Mg}$ & $39 \pm 4$ & $26 \pm 4$ & $29 \pm 4$ & $13 \pm 3^{*}$ & $17 \pm 4^{*}$ & $9 \pm 2 *$ & $6 \pm 2^{*}$ \\
\hline $\mathrm{H}_{2} \mathrm{O}$ & $89 \pm 1$ & $90 \pm 1$ & $89 \pm 1$ & $84 \pm 1^{*}$ & $88 \pm 1$ & $92 \pm 1$ & $89 \pm 1$ \\
\hline$n$ & 71 & 40 & 37 & 36 & 38 & 61 & 37 \\
\hline \multicolumn{8}{|c|}{ Small axons } \\
\hline $\mathbf{P}$ & $712 \pm 20$ & $766 \pm 20$ & $667 \pm 31$ & $625 \pm 31$ & $619 \pm 33$ & $565 \pm 22^{*}$ & $476 \pm 19 *$ \\
\hline $\mathrm{Cl}$ & $224 \pm 11$ & $236 \pm 10$ & $255 \pm 17$ & $173 \pm 10$ & $191 \pm 15$ & $191 \pm 14$ & $258 \pm 19 \dagger$ \\
\hline $\mathrm{Mg}$ & $27 \pm 3$ & $26 \pm 3$ & $12 \pm 3^{*}$ & $12 \pm 3^{*}$ & $19 \pm 3^{*}$ & $10 \pm 2^{*}$ & $4 \pm 1^{*}$ \\
\hline $\mathrm{H}_{2} \mathrm{O}$ & $88 \pm 1$ & $86 \pm 1$ & $85 \pm 1^{*}$ & $80 \pm 1^{*}$ & $84 \pm 1^{*}$ & $89 \pm 1$ & $86 \pm 1$ \\
\hline$n$ & 72 & 46 & 42 & 36 & 33 & 54 & 37 \\
\hline \multicolumn{8}{|c|}{ Mitochondrial area } \\
\hline $\mathrm{P}$ & $732 \pm 22$ & $720 \pm 38$ & $702 \pm 26$ & $565 \pm 30^{*}$ & $662 \pm 39$ & $713 \pm 35$ & $645 \pm 45$ \\
\hline $\mathrm{Cl}$ & $536 \pm 33$ & $410 \pm 35$ & $448 \pm 29$ & $340 \pm 28^{*}$ & $558 \pm 53 \dagger$ & $433 \pm 34^{*}$ & $547 \pm 49 \dagger$ \\
\hline $\mathbf{M g}$ & $39 \pm 5$ & $30 \pm 4$ & $29 \pm 4$ & $16 \pm 4^{*}$ & $14 \pm 3^{*}$ & $14 \pm 3^{*}$ & $10 \pm 3^{*}$ \\
\hline $\mathrm{H}_{2} \mathrm{O}$ & $84 \pm 1$ & $81 \pm 2$ & $84 \pm 1$ & $85 \pm 1$ & $83 \pm 2$ & $90 \pm 1^{*}$ & $86 \pm 2$ \\
\hline$n$ & 37 & 24 & 41 & 24 & 22 & 36 & 26 \\
\hline
\end{tabular}

Elemental data are expressed as mean $\mathrm{mmol} / \mathrm{kg}$ dry wt $\pm \mathrm{SEM} ; \mathrm{H}_{2} \mathrm{O}$ data are expressed as mean \% water $\pm \mathrm{SEM}$. $n$, Number of analyses per axon group or mitochondrial area.

* Mean data are significantly different from Normoxia as determined by ANOVA with Dunnett's $t$ test.

$\dagger$ Data variance is significantly different from that of normoxic control as determined by Kruskal-Wallis test with Mann-Whitney $U$ test.

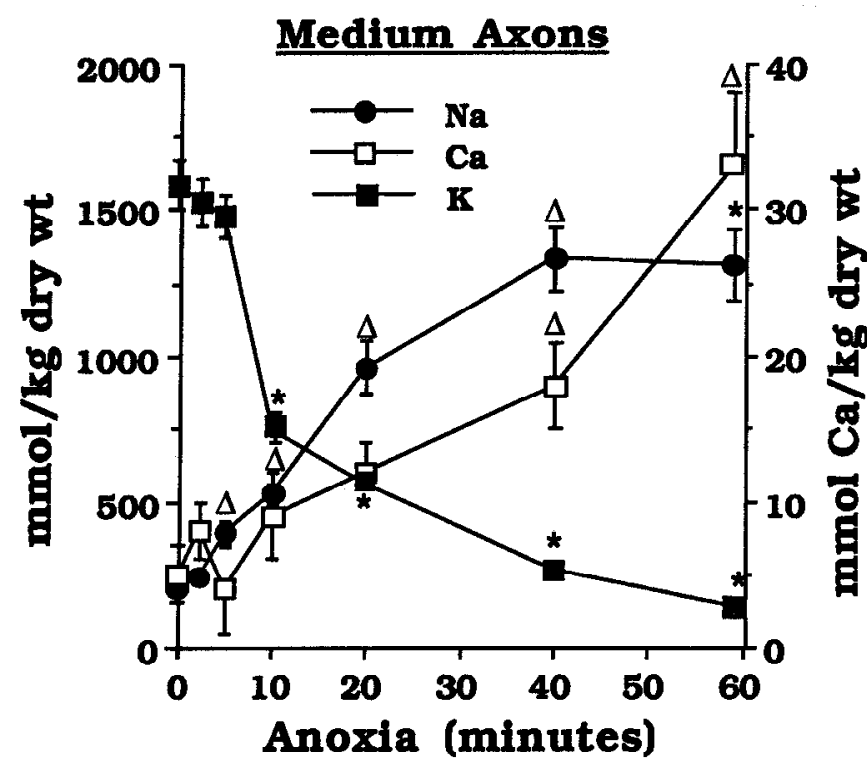

Figure 3. Effects of anoxia on mean ( \pm SEM) axoplasmic dry weight $\mathrm{Na}, \mathrm{Ca}$, and $\mathrm{K}$ concentrations of medium diameter optic nerve fibers. Left ordinate is concentration scale for $\mathrm{Na}$ and $\mathrm{K}$; right ordinate is the scale for $\mathrm{Ca} .{ }^{*}$, Mean data are significantly different $(p<0.05)$ from normoxic control as determined by ANOVA with Dunnett's $t$ test; $\Delta$, data variance is significantly different $(p<0.05)$ from that of normoxic control as determined by Kruskal-Wallis test with Mann-Whitney $U$ test. Number of fibers analyzed per expcrimental time point is provided in Table 2. concentrations increased slowly during the first $40 \mathrm{~min}$ of anoxia, and thereafter Ca levels rose abruptly (Fig. 2). Similar to large axon $\mathrm{Na}$, these changes in $\mathrm{Ca}$ content were characterized by significant increases in variance. Anoxia-induced losses of $\mathrm{Na}, \mathrm{K}$ and $\mathrm{Ca}$ regulation were associated with parallel perturbations in $\mathrm{Cl}, \mathrm{Mg}$, and water content (Table 2). Axoplasmic $\mathrm{Cl}$ concentrations in large axons decreased continuously during the initial $10 \mathrm{~min}$ of anoxia and then returned to normal over the next $50 \mathrm{~min}$ (Table 2). The $60 \mathrm{~min} \mathrm{Cl}$ data was associated with a statistically significant increase in variance. Mean dry weight $\mathrm{Mg}$ concentrations in large axons continued to fall during the entire anoxic period, whereas $\mathbf{P}$ level declined only slightly (Table 2). No changes in axoplasmic $S$ were observed (data not shown). These alterations in large axon elemental composition uccurred in conjunction with fluctuations in axonal water content. During the initial $10 \mathrm{~min}$ of anoxic exposure, mean percent water decreased significantly and then returned to slightly above normoxic values after continued oxygen deprivation (Table 2).

The temporal development and patterns of elemental alterations in medium diameter axons were similar to those occurring in large fibers (Fig. 3, Table 2). However, in small axons the onset of $\mathrm{Na}, \mathrm{K}$ and $\mathrm{Ca}$ derangements was early relative to that of larger axons (e.g., Fig. 4 vs Fig 2). The changes in axoplasmic $\mathrm{K}$ and $\mathrm{Na}$ concentrations in medium and small axons were not matched (i.e., $\mathrm{K}$ declined more than $\mathrm{Na}$ increased) during anoxia and therefore a net mean cationic deficit existed after $60 \mathrm{~min}$ of anoxia: medium fibers $=-19 \%$, small fibers $=-28 \%$. Charge 


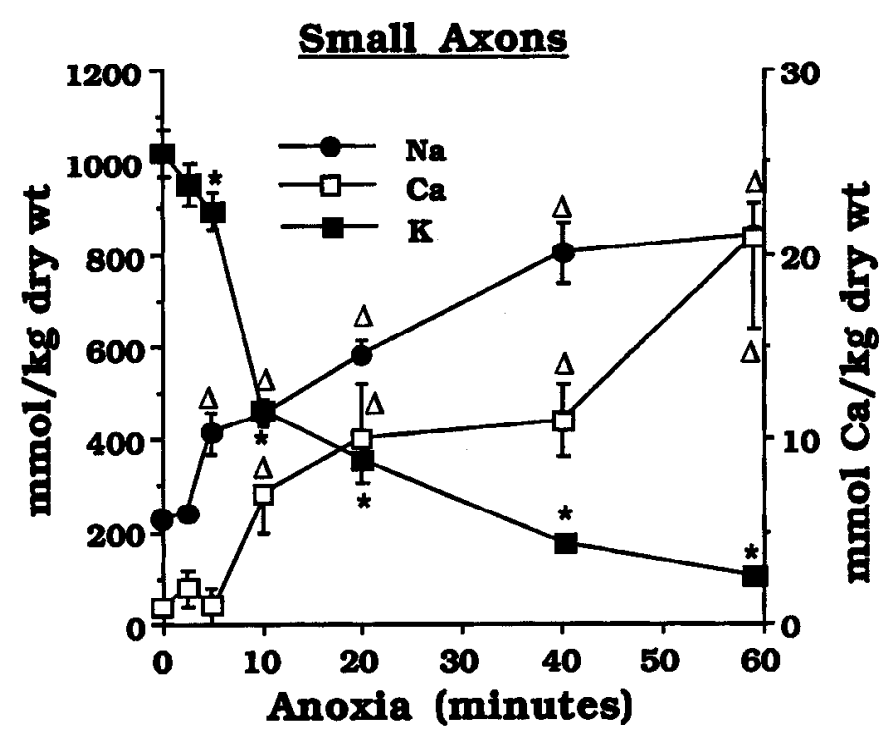

Figure 4. Effects of anoxia on mean ( \pm SEM) axoplasmic dry weight $\mathrm{Na}, \mathrm{Ca}$, and $\mathrm{K}$ concentrations of small diameter optic nerve fibers. Left ordinate is concentration scale for $\mathrm{Na}$ and $\mathrm{K}$; right ordinate is the scale for $\mathrm{Ca} .{ }^{*}$, Mean data are significantly different $(p<0.05)$ from normoxic control as determined by ANOVA with Dunnett's $t$ test; $\Delta$, data variance is significantly different $(p<0.05)$ from that of normoxic control as determined by Kruskal-Wallis test with Mann-Whitney $U$ test. Number of fibers analyzed per experimental time point is provided in Table 2.

appears to be maintained by a parallel loss of axoplasmic P: medium fibers $=-21 \%$, small fibers $=-33 \%$. The changes in mean $\mathrm{Mg}$ and water contents are also presented in Table 2.

In reoxygenated rat optic nerve, mean dry weight axoplasmic $\mathrm{K}$ of large and medium axons was increased modestly relative to anoxia (Fig. 5A,B). This increase was due to small subpopulations $(\approx 10-15 \%)$ of fibers that expressed elevated axoplasmic $\mathrm{K}$ relative to other members of these size groups. As a consequence, the dispersion of the respective data was greater than that of normoxia and associated variances were significantly increased $(p<0.05)$. For large axons, mean axoplasmic dry wt $\mathrm{Na}$ remained similar to anoxic levels (Fig. 6A). However, $\mathrm{Na}$ content of medium axons rose and a significant increase in variance was detected (Fig. $6 B$ ). This is attributed to the development of a subpopulation of axons that exhibited elevated $\mathrm{Na}$ levels (i.e., data above the 50th percentile) relative to the distribution of anoxic $\mathrm{Na}$ concentrations, while remaining medium axons displayed concentrations similar to or below the anoxia data (Fig. 6B). In contrast to larger axons, the distribution of $\mathrm{K}$ concentrations in small fibers revealed the presence of a subpopulation with elevated $\mathrm{K}$ when compared to the anoxic distribution (Fig. 5C, $>50$ th percentile). Small axons with $\mathrm{K}$ concentrations approaching normoxic values tended to have $\mathrm{Na}$ levels (Fig. 6C) that were much less than those associated with anoxia. Conversely, the subpopulation of axons whose distribution of $\mathrm{K}$ concentrations was similar to that of anoxic fibers (Fig. $5 \mathrm{C},<50$ th percentile) tended to have $\mathrm{Na}$ concentrations that were greater than those of anoxic axons (Fig. $6 \mathrm{C}$ ). Taken together, our data reveal that reoxygenated axons show either a tendency toward normalization of elemental composition, or exhibit persistent and severe elemental deregulation. A greater proportion of small axons displayed recovery compared to larger fibers. For most axons, that is, those not demonstrating a trend toward normalization, gains in mean axoplasmic $\mathrm{Na}$ were
Potassium
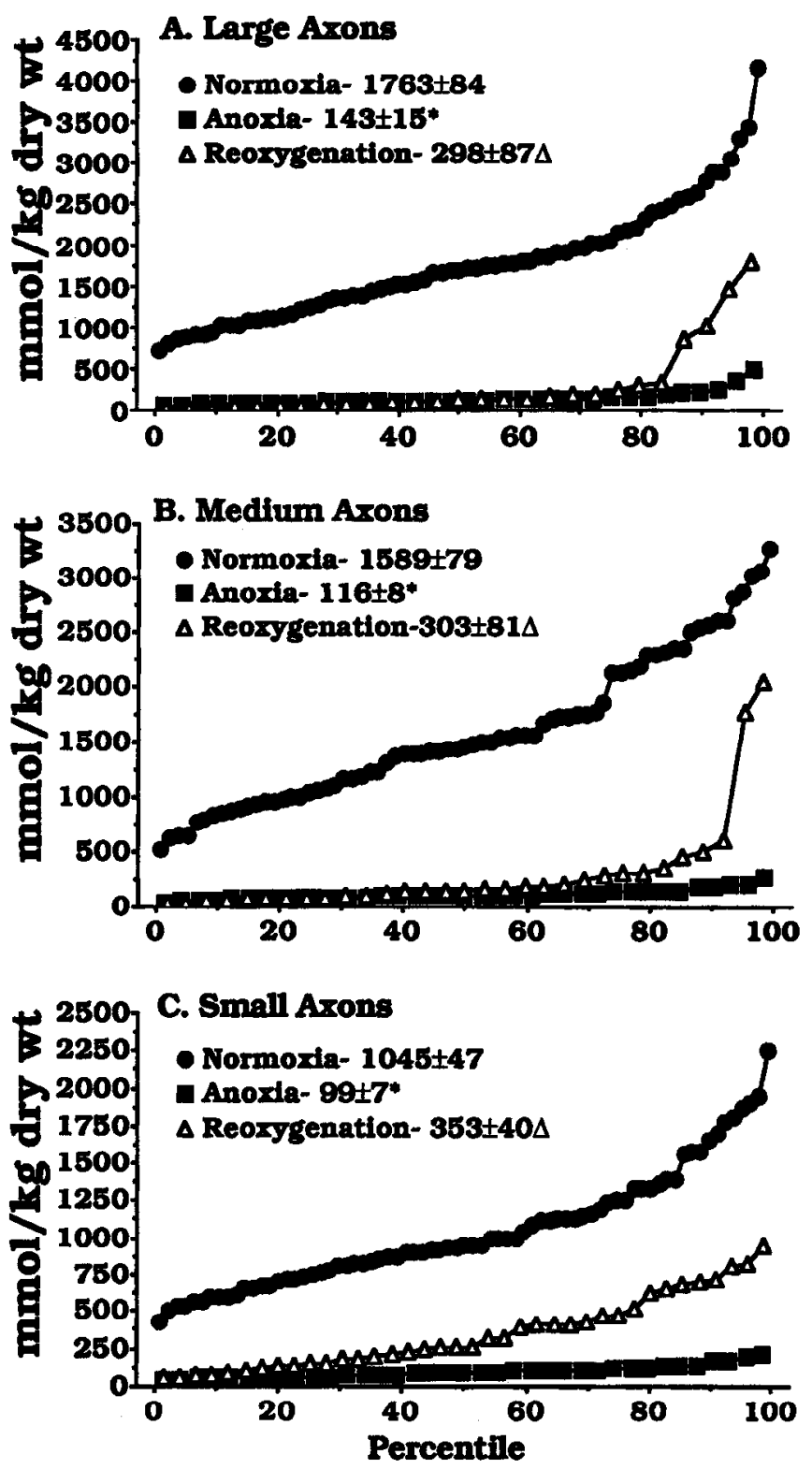

Figure 5. Percentile distributions of dry weight $\mathrm{K}$ concentrations in axoplasm of large $(A)$, medium $(B)$, and small $(C)$ diameter myelinated axons exposed to normoxia, 60 minutes of anoxia or 60 min of postanoxia reoxygenation. The respective distributions of $K$ concentrations show that during reoxygenation, small groups of large and medium fibers exhibit a trend toward normalization of axoplasmic $K$ when compared to the $\mathrm{K}$ distributions of anoxic axons. In contrast, a larger portion of small fibers exhibit partial recovery of $\mathrm{K}$ content during $60 \mathrm{~min}$ of postanoxia reoxygenation. Axons demonstrating a relative increase in $\mathbf{K}$ contents showed parallel improvements in axoplasmic Na concentrations. Mean dry weight $\mathrm{K}$ concentrations $(\mathrm{mmol} / \mathrm{kg}$ dry wt $\pm \mathrm{SEM}$ ) for each experimental condition are presented. *, Anoxia data are significantly different $(p<0.05)$ from normoxic control results; $\Delta$, variance of reoxygenation data is significantly different $(p<0.05)$ from that of anoxia as determined by Kruskal-Wallis and Mann-Whitney $U$ tests.

matched by losses of $\mathrm{K}$, therefore, net axonal cationic contents were equivalent to normoxic controls (Figs. 5, 6). Furthermore, reoxygenated axons exhibited increases in axoplasmic $\mathrm{P}, \mathrm{Cl}$, and $\mathrm{Mg}$ when compared to anoxic values (Table 3 ). Most notably, mean axoplasmic Ca levels of these fibers increased significantly (Table 3). 

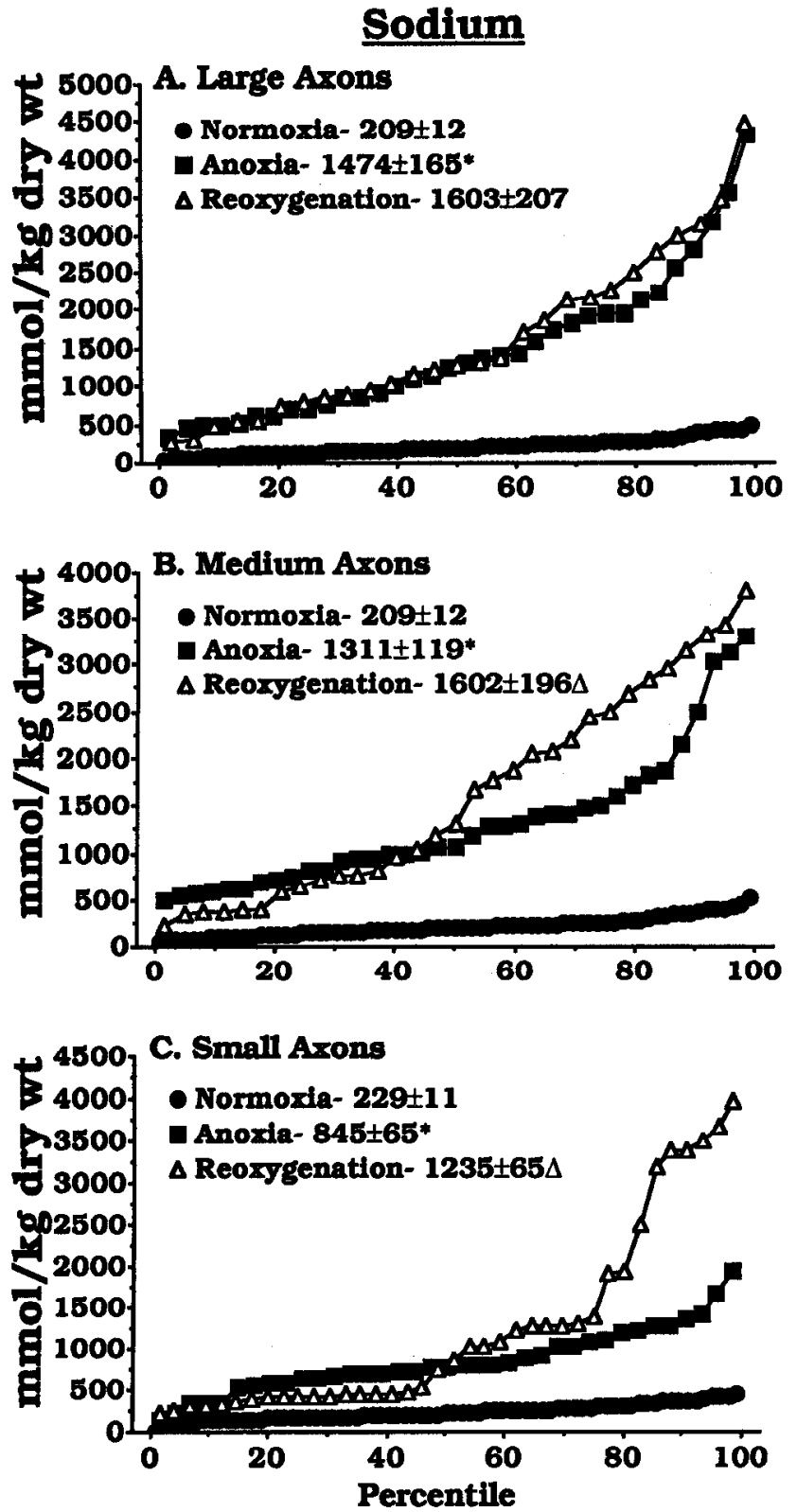

Figure 6. Percentile distributions of dry weight Na concentrations in axoplasm of large $(A)$, medium $(B)$, and small $(C)$ diameter myelinated axons exposed to normoxia, $60 \mathrm{~min}$ of anoxia or $60 \mathrm{~min}$ of postanoxia reoxygenation. The distribution of $\mathrm{Na}$ concentrations for large fibers from reoxygenated optic nerve is similar to that of large anoxic axons. In contrast, the $\mathrm{Na}$ distributions of medium and small reoxygenated fibers suggest the presence of subpopulations of respondents, that is, axons that display supra-anoxic $\mathrm{Na}$ contents, $\mathrm{Na}$ concentrations similar to those of anoxic axons and fibers that express normal to nearly normal $\mathrm{Na}$ levels. In these latter fibers, an improvement in $\mathrm{Na}$ content was correlated with elevated $\mathrm{K}$ levels when compared to respective anoxic values (see Fig. 5). Mean dry weight $\mathrm{Na}$ concentrations ( $\mathrm{mmol} / \mathrm{kg}$ dry wt \pm SEM) for each experimental condition are presented. *, Anoxia data are significantly different $(p<0.05)$ from normoxic control results; $\Delta$, variance of reoxygenation data is significantly different $(p<0.05)$ from that of anoxia as determined by Kruskal-Wallis and Mann-Whitney $U$ tests.

Effects of anoxia and reoxygenation on elemental composition and water content of axonal mitochondrial areas. During anoxia, mitochondrial areas from large and medium diameter fibers exhibited temporal patterns of element and water disruption that
Table 3. Elemental composition of myelinated axons and mitochondrial areas during postanoxia reoxygenation

\begin{tabular}{|c|c|c|c|}
\hline & Normoxia & Anoxia & Reoxygenation \\
\hline \multicolumn{4}{|c|}{ Large axons } \\
\hline $\mathrm{P}$ & $629 \pm 24$ & $592 \pm 25$ & $648 \pm 61 \dagger$ \\
\hline $\mathrm{Cl}$ & $492 \pm 23$ & $542 \pm 69$ & $774 \pm 127 \dagger$ \\
\hline $\mathrm{Ca}$ & $5 \pm 2$ & $42 \pm 9$ & $63 \pm 11^{*}$ \\
\hline $\mathrm{Mg}$ & $36 \pm 4$ & $6 \pm 2$ & $18 \pm 5^{*}$ \\
\hline $\mathrm{H}_{2} \mathrm{O}$ & $91 \pm 0$ & $91 \pm 1$ & $90 \pm 1$ \\
\hline$n$ & 69 & 34 & 27 \\
\hline \multicolumn{4}{|c|}{ Medium axons } \\
\hline $\mathbf{P}$ & $663 \pm 23$ & $526 \pm 30$ & $699 \pm 55 \dagger$ \\
\hline $\mathrm{Cl}$ & $426 \pm 22$ & $457 \pm 46$ & $616 \pm 104 \dagger$ \\
\hline $\mathrm{Ca}$ & $3 \pm 2$ & $33 \pm 5$ & $57 \pm 13 \dagger$ \\
\hline $\mathrm{Mg}$ & $39 \pm 4$ & $6 \pm 2$ & $19 \pm 5^{*}$ \\
\hline $\mathrm{H}_{2} \mathrm{O}$ & $89 \pm 1$ & $89 \pm 1$ & $90 \pm 1$ \\
\hline$n$ & 71 & 37 & 31 \\
\hline \multicolumn{4}{|c|}{ Small axons } \\
\hline $\mathbf{P}$ & $712 \pm 20$ & $476 \pm 19$ & $773 \pm 44 \dagger$ \\
\hline $\mathrm{Cl}$ & $224 \pm 11$ & $258 \pm 19$ & $500 \pm 99 \dagger$ \\
\hline $\mathrm{Ca}$ & $1 \pm 1$ & $21 \pm 5$ & $65 \pm 21 \dagger$ \\
\hline $\mathrm{Mg}$ & $27 \pm 3$ & $4 \pm 1$ & $18 \pm 5 \dagger$ \\
\hline $\mathrm{H}_{2} \mathrm{O}$ & $88 \pm 0$ & $86 \pm 1$ & $87 \pm 1$ \\
\hline$n$ & 72 & 37 & 38 \\
\hline \multicolumn{4}{|c|}{ Mitochondrial areas } \\
\hline $\mathrm{Na}$ & $168 \pm 12$ & $1612 \pm 144$ & $2559 \pm 328 \dagger$ \\
\hline $\mathbf{P}$ & $732 \pm 22$ & $645 \pm 44$ & $1421 \pm 169 \dagger$ \\
\hline $\mathrm{Cl}$ & $536 \pm 33$ & $547 \pm 49$ & $1082 \pm 157 \dagger$ \\
\hline $\mathbf{K}$ & $1849 \pm 107$ & $156 \pm 15$ & $532 \pm 143 \dagger$ \\
\hline $\mathrm{Ca}$ & $6 \pm 2$ & $22 \pm 4$ & $830 \pm 245 \dagger$ \\
\hline $\mathbf{M g}$ & $39 \pm 5$ & $10 \pm 3$ & $41 \pm 11 \dagger$ \\
\hline $\mathrm{H}_{2} \mathrm{O}$ & $85 \pm 1$ & $86 \pm 2$ & $83 \pm 2$ \\
\hline$n$ & 37 & 26 & 36 \\
\hline
\end{tabular}

Elemental data are expressed as mean mmol/kg dry wt $\pm \mathrm{SEM} ; \mathrm{H}_{2} \mathrm{O}$ data are expressed as mean \% water \pm SEM. Normoxia, normoxic controls; anoxia, mean dry wt axoplasmic data from optic nerves exposed to $60 \mathrm{~min}$ of in vitro anoxia; reoxygenation, mean dry wt axoplasmic data from optic nerves exposed to $60 \mathrm{~min}$ of in vitro anoxia followed by $60 \mathrm{~min}$ of normoxic reperfusion. Normoxic control data are presented for reference; see Table 2 for corresponding statistical comparisons of normoxic and anoxic data. $n$, Number of analyses per axon sizc group or mitochondrial area.

* Mean reoxygenation data are significantly different from anoxia as determined by ANOVA with Dunnett's $t$ test.

$\dagger$ Variance of reoxygenation data is significantly different from that of anoxia as determined by Kruskal-Wallis test with Mann-Whitney $U$ test.

were similar to changes in respective axoplasm (Fig. 7). Thus, mitochondrial $\mathrm{Na}$ concentrations rose rapidly during the first 20 min and proceeded at a slower rate as oxygen deprivation continued. Mean mitochondrial $\mathrm{K}$ concentrations exhibited early, rapid and progressive decreases while mean $\mathrm{Ca}$ levels remained normal for up to $10 \mathrm{~min}$ of anoxic exposure. Thereafter, mitochondrial $\mathrm{Ca}$ content rose rapidly to a maximum $(31 \pm 5 \mathrm{mmol}$ kg dry wt \pm SEM at $40 \mathrm{~min}$ ) and then decreased modestly (22 \pm 3 at $60 \mathrm{~min}$; Fig. 7). Anoxia-induced changes in mitochondrial $\mathrm{P}, \mathrm{Cl}, \mathrm{Mg}$, and water are presented in Table 2 . Following $60 \mathrm{~min}$ of postanoxia reoxygenation, mitochondrial areas from reoxygenated axons exhibited an exacerbation of the elemental derangement associated with anoxia (Table 3). The clcmental composition of reoxygenated mitochondria is highly heterogeneous, for example, $\mathrm{Na}$ concentrations range form normal (200-400 $\mathrm{mmol} / \mathrm{kg}$ dry wt) to greater than $5000 \mathrm{mmol} / \mathrm{kg}$. This wide data 


\section{Mitochondrial Areas}

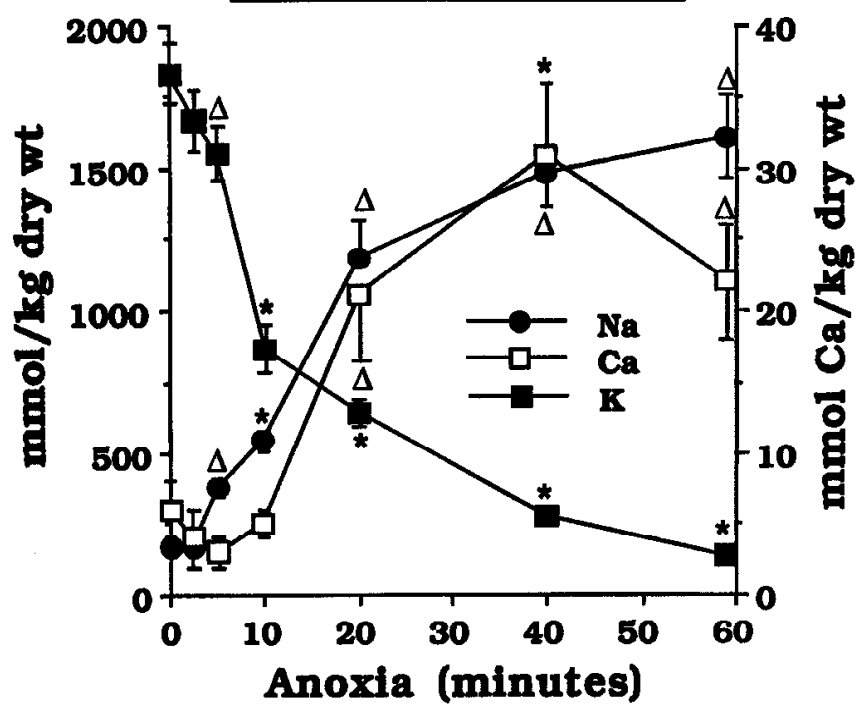

Figure 7. Effects of anoxia on mean ( \pm SEM) dry weight $\mathrm{Na}, \mathrm{Ca}$, and $\mathrm{K}$ concentrations of mitochondrial areas from large and medium diameter optic nerve fibers. Left ordinate is concentration scale for $\mathrm{Na}$ and $\mathrm{K}$; right ordinate is the scale for $\mathrm{Ca} .{ }^{*}$, Mean data are significantly different $(p<0.05)$ from normoxic control as determined by ANOVA with Dunnett's $t$ test; $\Delta$, data variance is significantly different $(p<$ 0.05 ) from that of normoxic control as determined by Kruskal-Wallis test with Mann-Whitney $U$ test. Number of mitochondrial areas analyzed per experimental time point is provided in Table 2 .

dispersion is reflected in corresponding statistically significant increases in variance for each element (Table 3). Perhaps the most notable changes in mitochondrial areas of reoxygenated axons were the marked increases in $\mathrm{Ca}$ and $\mathrm{P}$ relative to anoxic levels (Table 3).

Effects of anoxia and reoxygenation on elemental composition and water content of rat optic nerve glia and myelin. Both glial cell regions and myelin exhibited modest changes during anoxic exposure. After $60 \mathrm{~min}$ of anoxia, small but significant increases in mean $\mathrm{Na}$ and decreases in $\mathrm{K}$ were observed in both morphological compartments (Table 4). Reoxygenation was associated with a further slight depression of glial $\mathrm{K}$ with no additional changes in other elements or water (data not shown).

\section{Discussion}

Results of the present study demonstrate that in vitro exposure of rat optic nerves to anoxia causes early and progressive decreases in axoplasmic $K$ concentrations in conjunction with increases in the Na content of large, medium, and small diameter myelinated axons. These changes in $\mathrm{Na}$ and $\mathrm{K}$ are accompanied by increases in intraaxonal $\mathrm{Ca}$. Mitochondrial areas exhibited similar, parallel alterations in elemental composition. The close temporal relationship between axoplasmic and mitochondrial elemental deregulation, and parallel decline in compound action potential during optic nerve anoxia (Stys et al., 1990; see below), suggest that CNS myelinated axons have little energy reserve and are critically dependent upon aerobic metabolism for maintenance of ionic gradients and, therefore, excitability. Anoxia-induced alterations in optic nerve intraaxonal $\mathrm{Na}, \mathrm{K}$, and $\mathrm{Ca}$ are temporally correlated to the expression of structural and functional deficits and are, therefore, likely to be mechanistically relevant. For example, in previous electrophysiological studies, optic nerve compound action potential was completely abolished after $10 \mathrm{~min}$ of in vitro anoxia (Stys et al., 1990). Loss of electrophysiological function is likely due to the substantial decrease in axoplasmic $\mathrm{K}$ (with a concomitant rise in $\mathrm{K}^{+}{ }_{0}$; Ransom et al., 1992) and gain in $\mathrm{Na}$ occurring at this experimental time point (Figs. 2-4, Table 5). After 60 min of in vitro anoxia, morphological perturbation of optic nerve axons is well developed, for example, axonal cytoskeletal dissolution and mitochondrial swelling are evident (Waxman et al., 1992, 1994; Fig. 1 this

Table 4. Effects of anoxia on rat optic nerve glial cells and myelin



Elemental data are expressed as mean $\mathrm{mmol} / \mathrm{kg}$ dry $\mathrm{wt} \pm \mathrm{SEM} ; \mathrm{H}_{2} \mathrm{O}$ data are expressed as mean $\%$ water \pm SEM. $n$, Number of compartmental analyses per time point.

* Significantly $(p<0.05)$ different from normoxic control as determined by ANOVA with Dunnett's $t$ test. 
Table 5. Calculated mean millimolar concentrations of axonal elements

\begin{tabular}{|c|c|c|c|c|c|c|c|c|}
\hline & \multirow[b]{2}{*}{ Normoxia } & \multicolumn{6}{|c|}{ Anoxia $(\mathrm{min})$} & \multirow[b]{2}{*}{ Reoxy } \\
\hline & & 2.5 & 5 & 10 & 20 & 40 & 60 & \\
\hline \multicolumn{9}{|l|}{$\mathrm{Na}$} \\
\hline $\operatorname{Lg} \mathrm{Ax}$ & 16 & 18 & 27 & 54 & 83 & 68 & 93 & 135 \\
\hline Md Ax & 17 & 21 & 34 & 69 & 86 & 63 & 106 & 135 \\
\hline Sm Ax & 24 & 29 & 46 & 82 & 77 & 63 & 89 & 105 \\
\hline \multicolumn{9}{|l|}{$\mathbf{K}$} \\
\hline $\operatorname{Lg~Ax}$ & 162 & 153 & 161 & 110 & 56 & 17 & 13 & 30 \\
\hline Md Ax & 151 & 150 & 156 & 108 & 60 & 17 & 12 & 31 \\
\hline Sm Ax & 119 & 131 & 127 & 97 & 54 & 18 & 14 & 48 \\
\hline \multicolumn{9}{|l|}{$\mathrm{Cl}$} \\
\hline $\operatorname{Lg} A x$ & 50 & 46 & 54 & 47 & 45 & 26 & 46 & 86 \\
\hline Md Ax & 45 & 42 & 46 & 45 & 43 & 23 & 50 & 68 \\
\hline Sm Ax & 29 & 37 & 40 & 41 & 33 & 20 & 37 & 75 \\
\hline
\end{tabular}

Mean aqueous concentrations (mM) for each element were calculated using individual axoplasmic mmol element/ $\mathrm{kg}$ dry wt concentrations and corresponding \% water content. Calculations of aqueous concentrations were corrected assuming the following free fractions of intracellular elements: $\mathrm{K}=0.9, \mathrm{Na}=0.76$ (Hinke, 1961; Caldwell, 1968), and $\mathrm{Cl}=1.0$ (Alvarez-Leefmans et al., 1990). Ionized $\mathrm{Ca}$ was not estimated because of the very low free fraction in cells.

study). These structural alterations are probable consequences of the axonal $\mathrm{Ca}$ accumulation and generalized elemental disruption identified in the present study. Finally, the quantitative changes in axuplasmic and milochondrial $\mathrm{Ca}$ (i.e., 5-20-fold rise) associated with anoxia are equivalent to those observed in peripheral axons undergoing active Wallerian degeneration and predegenerative, swollen axons from peripheral nerve of acrylamide-intoxicated rat (LoPachin et al., 1990, 1992). This implies that the magnitude of intraaxonal $\mathrm{Ca}$ accumulation is causally related to axon injury in anoxic rat optic nerve.

Among axons of a given size, statistically significant changes in axonal $\mathrm{K}$ are expressed as mean population shifts whereas changes in $\mathrm{Na}$ and $\mathrm{Ca}$ concentrations are heterogeneous and, thus, primarily represented by increases in variance. The pathophysiological basis for this contrast in statistical expression is unknown but might represent differences in axonal processing of these elements. Thus, the subaxonal distribution of $\mathrm{Na}$ and Ca following anoxia-induced entry is a product of multiple regulatory influences involving exchangers $\left(\mathrm{Na}^{+}-\mathrm{Ca}^{2+}\right.$ exchanger $)$, residual membrane ion pump activities $\left(\mathrm{Na}^{+} / \mathrm{K}^{+-}, \mathrm{Ca}^{2+} / \mathrm{Mg}^{2+}\right.$ ATPases), buffering by organelles (SER, mitochondria) and passive binding. On an individual axon basis, variable expression of these homeostatic processes during the development of anoxia might be responsible for observed increases in variance associated with $\mathrm{Na}$ and $\mathrm{Ca}$ concentrations. In contrast, anoxia-related axoplasmic concentrations of $\mathrm{K}$ are not a product of complicated disposition kinetics but rather are due to simple efflux presumably via internodal $\mathrm{K}^{+}$channels (Waxman and Ritchie, 1985). Consequently, expression of axonal $\mathrm{K}$ content is less likely to be heterogeneous.

The mechanism of $\mathrm{Na}^{+}, \mathrm{K}^{+}$, and $\mathrm{Ca}^{2+}$ deregulation during anoxia has not been fully characterized. Stys et al. (1992) have proposed that $\mathrm{Ca}^{2+}$ entry into axons injured by anoxia is mediated by reverse operation of the membrane $\mathrm{Na}^{+}-\mathrm{Ca}^{2+}$ exchanger. This hypothesis is based on indirect electrophysiological and pharmacological evidence that suggests a sequential derangement of $\mathrm{Na}, \mathrm{K}$, and $\mathrm{Ca}$ levels in affected axons (Ransom et al., 1992; Stys et al., 1990, 1991, 1992). In the present study these and other biologically relevant elements were measured directly using electron probe $x$-ray microanalysis (EPMA). The coordinated loss of $\mathrm{Na}$ and $\mathrm{K}$ gradients is compatible with failure of axolemmal $\mathrm{Na}^{+} / \mathrm{K}^{+}$-ATPase activity and precedes increases in subaxonal $\mathrm{Ca}$. Recent evidence suggests that transmembrane $\mathrm{Na}^{+}$movement during anoxia occurs via a TTX-sensitive, noninactivating $\mathrm{Na}^{+}$conductance (Stys et al., 1992, 1993; Taylor, 1993). The increase in axonal $\mathrm{Na}$ in association with $\mathrm{K}$ efflux and, consequently, membrane depolarization, creates conditions that favor $\mathrm{Ca}^{2+}$ import via reverse $\mathrm{Na}^{+}-\mathrm{Ca}^{2+}$ exchanger (Baker, 1969; Cervetto et al., 1989; Dipolo and Beauge, 1988). Thus, these patterns of axonal elemental perturbation are consistent with the injury cascade proposed by Stys et al. (1992), that is, (1) anoxia-induced depletion of ATP, (2) rcduced $\mathrm{Na}^{+}$pump activity, (3) loss of transmembrane $\mathrm{Na}^{+}$gradients, (4) reverse operation of the $\mathrm{Na}^{+}-\mathrm{Ca}^{2+}$ exchanger, and (5) subsequent entry of damaging quantities of $\mathrm{Ca}^{2+}$.

Relative to respective axoplasm, mitochondrial areas from anoxic axons exhibit a large increase in $\mathrm{Ca}$ content during early anoxia (i.e., $20 \mathrm{~min}$ ). This probably reflects the $\mathrm{Ca}^{2+}$ buffering capacity of mitochondria (Nicholls, 1985; Carafoli, 1987) and suggests that $\mathrm{Ca}^{2+}$ influx during early anoxia is more extensive than indicated by corresponding axoplasmic levels. It is important to note that $\mathrm{Ca}$ accumulation by mitochondria progresses over $40 \mathrm{~min}$ of anoxia and then declines slightly (see Fig. 7). Cessation of sequestration, in spite of high axoplasmic $\mathrm{Ca}$ levels, might reflect severe loss of mitochondrial membrane potential with subsequent failure of electrophoretic $\mathrm{Ca}^{2+}$ uptake (Carafoli, 1987; Gunter and Pfeiffer, 1990). Regardless, this failure of $\mathrm{Ca}^{2+}$ buffering is reversible since during optic nerve reoxygenation extensive mitochondrial $\mathrm{Ca}^{2+}$ uptake resumes (see ahead).

Following $60 \mathrm{~min}$ of postanoxia reoxygenation, the majority of optic nerve axons exhibited severe elemental disruption with axonal and mitochondrial $\mathrm{Ca}$ levels that exceeded those associated with anoxia. It is assumed that these axons are irreversibly injured given the magnitude of $\mathrm{Na}$ and $\mathrm{Ca}$ disruption and their failure to express any potential for recovery (see ahead). The mechanism(s) of axonal reoxygenation injury is unknown. As indicated above, CNS myelinated axons appear to be critically dependent on aerobic energy metabolism and, therefore, mito- 
chondrial dysfunction during reoxygenation will be a primary determinant of axon injury. In most reoxygenated axons, mitochondrial areas exhibit massively elevated $\mathrm{Ca}$ and $\mathrm{P}$ levels suggesting the formation of calcium phosphate complexes (see review by Nicholls and Akerman, 1982). Since mitochondrial $\mathrm{Ca}^{2+}$ uptake occurs at the expense of ATP production (Nicholls, 1985; Nicholls and Akerman, 1982), disrupted aerobic ATP synthesis and subsequent energy deficit might contribute to the demise of reoxygenated optic nerve axons. It has also been suggested that during reoxygenation, the formation of free radicals is superimposed on the preexisting ionic disruption and, as a consequence, the magnitude of injury induced by anoxia is exacerbated (Fiskum, 1985; Cao et al., 1988; Patt et al., 1988; Halliwell, 1992; Watson et al., 1994). However, the role of free radical formation in mediating axonal elemental disruption in the present study remains to be determined.

Despite irreversible injury to most optic nerve fibers, small subpopulations of all axon groups exhibited trends toward restoration of axoplasmic concentrations of $\mathrm{Na}, \mathrm{K}$, and other elements after reoxygenation. Ionic restoration in axon subpopulations might be the basis for partial (30\% of control) recovery of rat optic nerve compound action potential previously identified following $60 \mathrm{~min}$ of postanoxic reoxygenation (Stys et al., $1990,1992)$. It is remarkable and somewhat paradoxical that most of the recovering fibers were from the small diameter group. Small axons have a relatively large surface-to-volume ratio, and they have high rates of metabolism and limited energy reserves (Gerard, 1927; Brody, 1966). Moreover, earlier studies suggest that these fibers are selectively vulnerable to anoxia (Gelfan and Tarlov, 1956). Thus, small axons seem unlikely candidates to express recovery potential. The functional traits responsible for resistance to anoxia and reoxygenation injury are, at present, unknown but might involve more effective $\mathrm{Ca}^{2+}$ homeostasis and buffering of free radicals or greater resistance to other injurious secondary events. The selective trend toward recovery by small axons and the severe elemental derangement of larger fibers correlates well with morphological observations which show that larger axons continue to exhibit pathologic changes (mitochondrial swelling, axoplasmic dissolution) despite 60 min of postanoxia reoxygenation (Waxman et al., 1992). The limited ability of CNS myelinated axons to restore normal elemental composition is in marked contrast to the full recovery of PNS axons achieved during postanoxia reoxygenation (LoPachin et al., unpublished observations). This finding underscores the marked differences in anoxic susceptibility between PNS and CNS fibers (Utzschneider et al., 1991).

As indicated in the introductory section, EPMA measures total elemental concentrations (i.e., ionic + bound species) and water content (\% water) in subcellular compartments. From these data, the equivalent aqueous concentration (in $\mathrm{mM}$ ) of an element can be calculated assuming a specific free fraction and that this fraction remains constant during anoxia (Table 5). The estimated millimolar concentrations should be interpreted cautiously since the validity of these assumption is unproven. For axoplasmic elements that presumably have a large ionized fraction (e.g., $\mathrm{Na}, \mathrm{K}, \mathrm{Cl}$ ), such calculations might be reasonable estimates of respective free ion content; however, these calculations are inappropriate for other elements (e.g., Ca) where a significant bound fraction exists (Shporer and Civan, 1977; Walker and Brown, 1977). Although the axoplasmic ionic content of mammalian CNS axons is unknown, normoxic millimolar concentrations of $\mathrm{Na}^{+}$and $\mathrm{K}^{+}$calculated from our EPMA data
(Table 5) are comparable to earlier peripheral nerve axon measurements employing other techniques (Brismar, 1980; Frankenhaeuser, 1957; Walker and Brown, 1977). During $1 \mathrm{hr}$ of in vitro anoxia, the extent of axonal $\mathrm{K}$ loss exceeds $\mathrm{Na}$ gain. In addition, transient decreases in water content occur and, when elemental concentrations are calculated on a mM basis, a progressive net loss of osmolarity is revealed: e.g., Table 5, medium axon $[\mathrm{Na}+\mathrm{K}+\mathrm{Cl}]-$ normoxia $=213 \mathrm{~mm}$ versus $-60^{\prime}$ anoxia $=168$ $\mathrm{mM}$. In contrast, during reoxygenation many optic nerve axons continue to gain $\mathrm{Na}$ and/or loose $\mathrm{K}$ (see Figs. 5, 6) and, as a result, mean osmolarity is returned to slightly above normal; for example, Table 5, medium axon $[\mathrm{Na}+\mathrm{K}+\mathrm{Cl}]-$ normoxia $=$ $213 \mathrm{mM}$ versus - reoxygenation $=234 \mathrm{~mm}$. Whether these changes in osmolarity reflect anoxia-related events or methodological problems (e.g., inaccurate water measurements) is not known. However, we note that intracellular $\mathrm{K}^{+}$concentration is generally larger than necessary for electrochemical equilibrium. Therefore, since axolemmal $\mathrm{K}^{+}$permeability is greater than that of $\mathrm{Na}^{+}$, the rate of $\mathrm{K}^{+}$loss can exceed the rate of net $\mathrm{Na}^{+}$influx during anoxia. As a consequence, the net loss of $\mathrm{K}^{+}$will be associated with a transient decrease in cell volume. Eventually, the $\mathrm{K}^{+}$gradient will dissipate and water will enter in conjunction with continued $\mathrm{Na}^{+}$and $\mathrm{Cl}^{-}$entry (Macknight, 1984). In addition, osmoregulation during anoxia is a complex process (Macknight, 1984; Erecinska and Silver, 1994), and it is possible that net loss of element is offset by evolution of idiogenic osmoles such as lactate and/or metabolites of proteins and lipids which do not contribute to a net change in EPMA detected elemental composition (Hossman and Takagi, 1976; Hatashita et al., 1988; Erecinska and Silver, 1994).

Dry weight elemental composition of glial cells and myelin remained relatively unchanged up to $40 \mathrm{~min}$ of anoxia. Thereafter, both compartments exhibited modest but statistically significant changes in $\mathrm{Na}$ and $\mathrm{K}$. Other than a slight worsening of $\mathrm{K}$ loss, reoxygenation was not associated with an exacerbation of anoxia-induced effects. Alterations in glial cell $\mathrm{Ca}$ were not observed during either anoxia or reoxygenation. The patterns of glial cell elemental changes produced by anoxia and reoxygenation are consistent with reversible perturbation (LoPachin et al., 1992b) and, in agreement with others (Petito et al., 1990; Janeczko, 1991; Hertz et al., 1992; Hori et al., 1994), it appears that glia are relatively resistant to injury associated with oxygen deprivation and reoxygenation.

In summary, in vitro exposure of rat optic nerve to anoxia produces a sequential derangement of $\mathrm{Na}, \mathrm{K}$, and $\mathrm{Ca}$ concentration in myelinated axons. Postanoxia reoxygenation, rather than promoting recovery, exacerbates the preexisting elemental disruption and causes apparent irreversible injury in the majority of axons. However, in a subpopulation of mostly small axons, reoxygenation is associated with a trend toward normalization of elemental composition. In contrast to axons, glial cells display only modest changes in elemental composition and it is suggested that these cells are relatively resistant to anoxia/reoxygenation injury. The development of axonal elemental deregulation that occurs in response to in vitro anoxia and reoxygenation is temporally correlated to the onset of related structural and functional deficits. This suggests that these changes are an important mechanistic component of CNS white matter injury associated with anoxia. Furthermore, the pattern of elemental alteration in anoxic axons is consistent with $\mathrm{Ca}^{2+}$ entry via reverse operation of the axolemmal $\mathrm{Na}^{+}-\mathrm{Ca}^{2+}$ exchanger (Stys et al., 1992). This pattern is also similar to that produced by me- 
chanical, chemical, and ischemic injury of myelinated axons in CNS and PNS tissues (Hansen, 1985; Young and Koreh, 1986; Kwo et al., 1989; LoPachin et al., 1990, 1992a) and, therefore, it is possible that $\mathrm{Ca}^{2+}$ overload via reversal of $\mathrm{Na}^{+}-\mathrm{Ca}^{2+}$ exchange represents a general mechanism with possible implications for other forms of axon damage and degeneration. The present findings represent fundamental information concerning transmembrane movements of $\mathrm{Na}^{+}, \mathrm{K}^{+}, \mathrm{Ca}^{2+}$, and other ions during anoxia and reoxygenation, and provide a rational basis for further mechanistic investigations of myelinated axon injury in CNS white matter.

\section{References}

Alvarez-Leefmans FJ, Giraldez F, Russell JM (1990) Methods from measuring chloride transport across nerve, muscle, and glial cells. In: Chloride channels and carriers in nerve, muscle, and glial cells (Alvarez-Leefmans J, Russell JM, eds), pp 3-66. New York: Plenum.

Baker PF, Blaustein MP, Hodgkin AL, Steinhardt RA (1969) The influence of calcium on sodium efflux in squid axons. J Physiol (Lond) 200:431-458.

Blaustein MP (1988) Calcium transport and buffering in neurons. Trends Neurosci 11:438-443.

Brody IA (1964) Lactate dehydrogenase isoenzymes: a difference between cutaneous and muscular nerves. J Neurochem 13:975-978.

Brismar T (1980) Potential clamp analysis of membrane currents in rat myelinated nerve fibres. J Physiol (Lond) 298:171-184.

Bulger RE, Beeuwkes R and Saubermann AJ (1981) Application of scanning electron microscopy to $\mathrm{x}$-ray analysis of frozen-hydrated scctions. III. Elemental content of cells in the rat renal papillary tip. J Cell Biol 88:274-280.

Caldwell PC (1968) Factors governing movement and distribution of inorganic ions in nerve and muscle. Physiol Rev 48:1-64.

Cao W, Carney JM, Duchon A, Floyd RA, Chevion M (1988) Oxygen free radical involvement in ischemia and reperfusion injury to brain. Neurosci Lett 88:233-238.

Carafoli E (1987) Intracellular calcium homeostasis. Annu Rev Biochem 56:395-433.

Cervetto L, Lagnado L, Perry RJ, Robinson DW, McNaughton PA (1989) Extrusion of calcium from rod outer segments is driven by both sodium and potassium gradients. Nature 337:740-743.

Choi DW (1990) Cerebral hypoxia: some new approaches and unanswered questions. J Neurosci 10:2493-2501.

DiPolo R, Beauge L (1988) $\mathrm{Ca}^{2+}$ transport in nerve fibers. Biochim Biophys Acta 947:549-569.

Erecinska M, Silver IA (1994) Ions and energy in mammalian brian. Prog Neurobiol 43:37-71.

Farber JL (1981) Membrane injury and calcium homeostasis in the pathogenesis of coagulative necrosis. Lab Invest 47:114-123.

Fiskum G (1985) Mitochondrial damage during cerebral ischemia. Ann Emerg Med 14:810-815.

Foster MC, Saubermann AJ (1991) Personal-computer-based system for electron beam x-ray microanalysis of biological samples. J Microsc 161:367-373.

Frankenhaeuser B (1957) A method for recording resting and action potentials in the isolated myelinated nerve fiber of the frog. J Physiol (Lond) 135:550-559.

Gelfan S, Tarlov IM (1955) Differential vulnerability of spinal cord structures to anoxia. J Neurophysiol 18:170-188.

Gerard RW (1927) Studies on nerve metabolism. II. Respiration in oxygen and nitrogen. Am J Physiol 82:381-404.

Gunter TE, Pfeiffer DR (1990) Mechanisms by which mitochondria transport calcium. Am J Physiol 258(Cell Physiol 27):C755-C786.

Hall TA, Anderson HC, Appleton T (1973) The use of thin specimens for X-ray microanalysis in biology. J Microsc 99:177-182.

Halliwell B (1992) Reactive oxygen species and the central nervous system. J Neurochem 59:1609-1623.

Hatashita S, Hoff JT, Salamat SM (1988) Ischemic brain edema and the osmotic gradient between blood and brain. J Cereb Blood Flow Metab 8:552-559.

Hinke JAM (1961) The measurement of sodium and potassium activities in the squid axon by mcans of cation-selective glass microelectrodes. J Physiol (Lond) 156:314-335.
Hossman K-A, Takagi S (1976) Osmolality of brain in cerebral ischemia. Exp Neurol 51:124-131.

Janeczko K (1991) The proliferative response of S-100 protein-positive glial cells to injury in the neonatal rat brain. Brain Res 564:86-90.

Kimelberg HK, Ransom BR (1986) Physiological and pathological aspects of astrocytic swelling. In: The astrocytes (Fedoroff S, Vernadakis A, eds), pp 129-166, New York: Academic.

Kim-Lee MH, Stokes BT, Yates AJ (1992) Reperfusion paradox: a novel mode of glial cell injury. Glia 5:56-64.

Kwo S, Young W, DeCrescito V (1989) Spinal cord sodium, potassium, calcium and water concentration changes in rats after graded contusion injury. J Neurotruama 7:41-54

LoPachin RM, Saubermann AJ (1990) Disruption of cellular elements and water in neurotoxicity: studies using electron probe $\mathrm{x}$-ray microanalysis. Tox Appl Pharmacol 106:355-374.

LoPachin RM, Lowery J, Eichberg J, Kirkpatrick JB, Cartwright J, Saubermann AJ (1988) Distribution of elements in rat peripheral axons and nerve cell bodies determined by $\mathrm{x}$-ray microprobe analysis. J Neurochem 51:764-775.

LoPachin RM, LoPachin V, Saubermann A (1990) Effects of axotomy on distribution and concentration of elements in rat sciatic nerve. $\mathrm{J}$ Neurochem 54:320-332.

LoPachin RM, Castiglia CM, Saubermann AJ (1991) Elemental composition and water content of myelinated axons and glial cells in rat central nervous system. Brain Res 549:253-259.

LoPachin RM, Castiglia CM, Saubermann AJ (1992a) Acrylamide disrupts elemental composition and water content of rat tibial nerve. $I$. Myelinated axons. Toxicol Appl Pharmacol 115:21-34.

LoPachin RM, Castiglia CM, Saubermann AJ (1992b) Acrylamide disrupts elemental composition and water content of rat tibial nerve. II Schwann cells and myelin. Toxicol Appl Pharmacol 115:35-43.

LoPachin RM, Castiglia CM, Saubermann AJ, Eichberg J (1993) Ganglioside treatment modifies abnormal elemental composition in peripheral nerve myelinated axons of experimentally diabetic rats. J Neurochem 60:477-486.

Macknight ADC (1984) Cellular response to injury. In: Edema (Staub NC, Taylor AE, eds), pp 489-520. New York: Raven.

Macknight ADC (1988) Principles of cell volume regulation. Renal Physiol Biochem 35:114-141.

Nicholls DG (1985) A role for the mitochondrion in the protection of cells against calcium overload? In: Progress in brain research, Vol 63 (Kogure K, Hossmann KA, Siesjo K, Welsh FA, eds), pp 97-106. New York: Elsevier.

Nicholls DG, Akerman K (1982) Mitochondrial calcium transport. Biochim Biophys Acta 683:57-88.

Patt A, Harken AH, Burton LK, Rodell TC, Piermattei D, Schorr WJ, Parker NB, Berger EM, Horesh IR, Terade LS, Linas SL, Cheronis JC Repine JE (1988) Xanthine oxidase derived hydrogen peroxide contributes to ischemia reperfusion induced edema in gerbil brains. J Clin Invest 81:1556-1562.

Ransom BR, Philbin DM (1992) Anoxia-induced extracellular ionic changes in CNS white maller: the role of glial cells. Can J Physiol Pharmacol 70:S181-S189.

Ransom BR, Walz W, Davis PK, Carlina WG (1992) Anoxia-induced changes in extracellular $\mathrm{K}$ and $\mathrm{pH}$ in mammalian central white matter J Cereb Blood Flow Metab 12:593-602

Saubermann AJ, Heyman RV (1987) Quantitative digital X-ray imaging using frozen hydrated and frozen dried tissue sections. J Microsc 146: 169-182.

Saubermann AJ, Echlin P, Peters PD, Beeuwkes R (1981a) Application of scanning electron microscopy to $\mathrm{X}$-ray analysis of frozen-hydrated sections. I. Specimen handling techniques. J Cell Biol 88:257-267.

Saubermann AJ, Beeuwkes R, Peters PD (1981b) Application of scanning electron microscopy to $\mathrm{x}$-ray analysis of frozen-hydrated sections. II. Analysis of standard solutions and artificial electrolyte gradients. J Cell Biol 88:268-273.

Shporer M, Civan MM (1977) The state of water and alkali cations within the intracellular fluids: the contribution of NMR spectroscopy. In: Current topics in membranes and transport, Vol 9 (Bronner F, Kleinzeller A, eds), pp 1-69. New York: Academic.

Siesjo BK (1981) Cell damage in the brain: a speculative synthesis. I Cereb Blood Flow Metab 1:155-185.

Siesjo BK (1988) Mechanisms of ischemic brain damage. Crit Care Med 16:954-963.

Stys PK, Ransom BR, Waxman SG, Davis PK (1990) Role of extra- 
cellular calcium in anoxic injury of mammalian central white matter. Proc Natl Acad Sci USA 87:4212-4216.

Stys PK, Waxman SG, Ransom BR (1991) Na-Ca exchanger mediates calcium influx during anoxia in mammalian central nervous system white matter. Ann Neurol 30:375-380.

Stys PK, Waxman SG, Ransom BR (1992) Ionic mechanisms of anoxic injury in mammalian CNS white matter: role of $\mathrm{Na}$ channels and $\mathrm{Na}-$ Ca exchanger. J Neurosci 12:430-439.

Stys PK, Sontheimer H, Ransom BR, Waxman SG (1993) Non-inactivating, TTX-sensitive $\mathrm{Na}^{+}$conductance in rat optic nerve axons. Proc Natl Acad Sci USA 90:6976-6980.

Sykova E (1983) Extracellular $\mathrm{K}$ accumulation in the central nervous system. Prog Biophys Mol Biol 42:135-189.

Taylor DP (1993) $\mathrm{Na}^{+}$currents that fail to inactivate. Trends Neurosci $16: 455-460$

Utzschneider DA, Kocsis JD, Waxman SG (1991) Differential sensitivity to hypoxia of the peripheral versus central trajectory of primary afferent axons. Brain Res 551:136-141.

Walker JL, Brown HM (1977) Intracellular ionic activity measurements in nerve and muscle. Physiol Rev 57:729-787.

Watson BD, Busto R, Goldberg WJ, Santiso M, Yoshida S, Ginsberg
MD. (1984) Lipid peroxidation in vivo by reversible global ischemia in rat brain. $\mathrm{J}$ Neurochem 42:268-274.

Waxman SG, Ritchie JM (1985) Organization of ion channels in the myelinated nerve fiber. Science 228:1502-1507.

Waxman SG, Black JA, Stys PK, Ransom BR (1992) Ultrastructural concomitants of anoxic injury and early post-anoxic recovery in rat optic nerve. Brain Res 574:105-119.

Waxman SG, Black JA, Ransom BR, Stys PK (1993) Protection of the axonal cytoskeleton in anoxic optic nerve by decreased extracellular calcium. Brain Res 614:137-145.

Waxman SG, Black JA, Ransom BR, Stys PK (1994) Anoxic injury of rat optic nerve: ultrastructural evidence for coupling between $\mathrm{Na}^{+}$ influx and $\mathrm{Ca}^{2+}$-mediated injury in myelinated $\mathrm{CNS}$ axons. Brain Res 644:197-204.

Young W (1986) Ca paradox in neural injury: a hypothesis. Cent Nerv Syst Trauma 3:235-251.

Young W, Koreh I (1986) Potassium and calcium changes injured spinal cords. Brain Res 365:42-53.

Zoccarato F, Nicholls DG (1982) The role of phosphate in the regulation of the calcium efflux pathway of liver mitochondria. Eur J Biochem 127:333-338. 